\title{
O ENSINO DAS RELAÇÕES INTERNACIONAIS NO BRASIL: PROBLEMAS E PERSPECTIVAS ${ }^{1}$
}

\author{
Shiguenoli Miyamoto \\ Universidade Estadual de Campinas
}

\begin{abstract}
RESUMO
Em função das grandes transformações verificadas no mundo, na última década, ocorreu um rápido aumento na quantidade de cursos de Relações Internacionais (RI) no Brasil. Atualmente, há quase sessenta cursos em funcionamento. Percebe-se, todavia, é que nem sempre se asseguram condições adequadas para o funcionamento desses cursos. Deficiências podem ser observadas não só no corpo docente, como também nas bibliotecas, que muitas vezes não dispõem de acervo suficiente para atender às demandas das disciplinas ministradas. Juntamente com esses problemas, os egressos dos cursos de RI têm manifestado preocupações com sua inserção no mercado de trabalho, apesar de se encontrarem em uma área em plena expansão, e terem uma formação múltipla que os torna altamente competitivos. Neste artigo analisamos as condições sociais que criam a demanda pelo estudo das Relações Internacionais no Brasil, bem como as exigências legais e institucionais para o bom funcionamento dos cursos de graduação nessa área.
\end{abstract}

PALAVRAS-CHAVE: Relações Internacionais; qualidade no ensino de Relações Internacionais; exigências legais e institucionais; inserção no mercado de trabalho.

\section{A DEMANDA PELAS RELAÇÕES INTER- NACIONAIS}

"O que nós vamos ser quando crescer" (sic) perguntava, certa vez, aluno de graduação em Relações Internacionais da Pontifícia Universidade Católica de Minas Gerais (PUC-MG), em artigo publicado pelo jornal $O$ Estado de Minas. As preocupações por ele expostas diziam respeito a um sentimento de insegurança quanto ao futuro profissional e a um certo desânimo ou incômodo difíceis de explicar, sentidos por ele e seus colegas (VASCONCELOS, 1999). Isso se verificava, em certa medida, devido à grade curricular multidisciplinar do bacharelado em Relações Internacionais que não forma alunos com habilidades específicas, como a maioria dos cursos universitários.

Dúvidas dessa natureza não eram apenas dele, mas de grande parte de seus colegas que frequien-

\footnotetext{
1 Algumas informações aqui mencionadas só foram possíveis graças à colaboração dos professores Reginaldo Mattar Nasser e Henrique Altemani de Oliveira (PUC-SP), Eiiti Sato (UnB), além do graduando Eduardo Wirthmann Ferreira (FENERI). Agradeço a todos, ressalvando, contudo, que o texto ora apresentado é de minha inteira responsabilidade.
}

tam os cursos de Relações Internacionais, como ficou bastante claro nos debates ocorridos no V Encontro entre Estudantes e Graduados em Relações Internacionais do Conesul, realizado em Brasília, em outubro de 1999 (bem como em qualquer seminário sobre o assunto), vistos por centenas de estudantes de várias faculdades do país.

A preocupação com o futuro profissional e a obtenção de emprego não são prerrogativas ou motivo de apreensão exclusivos dos estudantes, ou dos recém-formados em Relações Internacionais, mas de todas as carreiras. Mesmo egressos de áreas tradicionais como a Medicina, a Odontologia, o Direito e a Engenharia, apenas para mencionar alguns, têm enfrentado problemas parecidos para conquistar espaços no mercado de trabalho, que se torna cada dia mais competitivo.

Novas profissões, por outro lado, têm surgido em número cada vez maior, em função das necessidades e lacunas existentes, com carência de profissionais habilitados em quantidade suficiente para atender as demandas do mercado. Entre essas áreas muito solicitadas temos, por exemplo, aquelas ligadas à tecnologia, à engenharia ambiental e sanitária, à biotecnologia, à informática, ao 
turismo, ao setor hoteleiro, ao gerenciamento de edifícios inteligentes, ao marketing, além do curso de Relações Internacionais (doravante mencionado como RI).

A procura por esses cursos tem sido grande. Vale a pena lembrar que o bacharelado em Relações Internacionais da Pontifícia Universidade Católica de São Paulo (PUC-SP), criado em 1995, tem-se mantido, desde o início, entre os três mais concorridos nos vestibulares realizados por aquela instituição, muitas vezes ficando em segundo lugar na preferência dos alunos, com mais de dez candidatos (tendo já chegado a 18) por vaga. Nos cursos de RI da Universidade de São Paulo (USP) e da Universidade Estadual Paulista Júlio de Mesquita Filho (UNESP), campus de Franca, a procura por uma das vagas é ainda maior. No primeiro vestibular de ambos, para ingresso em 2002, a proporção foi de 59 e 29 candidatos/vaga, tendo sofrido queda brusca para 37 e 18 candidatos/vaga, respectivamente, para o ano de 2003. Mesmo assim, permaneceram entre os cursos mais solicitados dessas universidades. Neste momento, são três as instituições públicas de ensino superior que mantêm cursos de graduação de RI no país: Universidade de Brasília (UnB), USP e UNESP.

O surgimento de dezenas de cursos de RI nos últimos anos - atualmente em torno de sessenta, autorizados pela Secretaria de Educação Superior (SESu) do Ministério da Educação ${ }^{2}$ - é um claro indicador de que há uma procura bastante acentuada, anteriormente reprimida, por carreiras como essa, em todo o país. As explicações para o aumento de interesse na área de RI podem ser creditadas à importância que o mundo globalizado, a formação dos megablocos e a informação instantânea, por meio da televisão aberta e a cabo, ou via internet, têm exercido sobre todos, rompendo distâncias e fronteiras, ligando países e continentes, com velocidades cada vez maiores, mostrando que os mesmos estão separados por apenas poucas horas de vôo, e que fazemos parte de um mundo muito pequeno.

O aumento da interdependência econômica, os intercâmbios em todos os planos, as influências culturais e sociais que se têm processado de

\footnotetext{
2 Pode-se achar a relação completa em http:// www.educacaosuperior.inep.gov.br.
}

maneira acelerada, sempre mais rapidamente, passaram a fazer parte do quotidiano, exigindo que o domínio de informações, o mais variado possível, adquirisse relevada importância, mesmo crucial, para todas as profissões ${ }^{3}$.

Nesse novo cenário, o que se constata é que não existe, ainda, no país, quantidade de profissionais suficientemente habilitados para atender a um mercado com tais necessidades. Daí o surgimento dos cursos não só de graduação em RI, mas também de dezenas de pós-graduação lato sensu e stricto sensu, abarcando gama variada de temas - com grande ênfase no comércio internacional -, como a globalização (sob os mais diferentes aspectos), os processos de integração, o Mercado Comum do Sul (Mercosul), a Área de Livre Comércio das Américas (ALCA), a Organização Mundial do Comércio (OMC), as negociações com a União Européia etc.

O número de instâncias surgidas nos anos mais recentes, tanto no plano governamental, quanto no setor empresarial, direcionadas para as relações internacionais é bastante visível.

A criação do Centro Brasileiro de Relações Internacionais (CEBRI), organização nãogovernamental, por iniciativa do então chanceler Luis Felipe Lampréia, caminha nessa mesma direção. Fundada em junho de 1998, a entidade cujo Diretor Executivo atual é Mário Marconini tem por missão, segundo seus dirigentes, criar "um espaço de estudos e debates que propiciará insumos para o processo decisório governamental e para a atuação do Governo em processos de negociação internacional” (BORGES, 1999, p. 03). Em suma, "o CEBRI pretende ser o mais importante think tank de políticas públicas na área externa do país" (ibidem). As áreas-alvo de interesse, inicialmente propostas e entendidas como prioritárias, constituindo-se núcleos de pesquisa

\footnotetext{
3 Alguns dos motivos que levaram à expansão da área de Relações Internacionais podem ser encontrados em meu texto O estudo das Relações Internacionais no Brasil: o estado da arte (MIYAMOTO, 1999). Ver o livro de Paulo Roberto de Almeida (1999b). Também os textos de José Ribas Vieira (1983) e Antônio Paulo Cachapuz de Medeiros (1979, especialmente p. 57-62). Não faço, neste momento, considerações teóricas sobre o ensino das relações internacionais, de maneira mais ampla, porque este problema está sendo objeto de um outro texto que preparo. Minha preocupação aqui é apenas levantar alguns pontos sobre o caso brasileiro.
} 
em torno delas, contemplavam quatro temas: o futuro do Mercosul, as perspectivas da Alca, a integração física da América do Sul, e a OMC e a regulação do comércio internacional: perspectivas pós-Seattle (ibidem).

Como se pode ver pela iniciativa tomada pelo então Presidente Fernando Henrique Cardoso, ao convidar os 11 demais países do continente sulamericano para participar da primeira reunião de cúpula da região, realizada nos dias 31 de agosto e $1^{\circ}$ de setembro de 2000, o CEBRI, antes mesmo de constituir-se efetivamente, já estava exercitando, num primeiro momento, o papel de interlocutor credenciado para discutir política externa com o governo brasileiro. Pela pauta proposta, podia-se ver que os quatro temas objeto de discussão no encontro contemplavam o reforço da democracia, o comércio, o combate ao crime organizado e a integração física do continente, tal como colocado pela entidade (LAMPRÉIA, 2000, p. A-2; ROSSI, 2000 , p. 1-5). Contudo, em função de alguns problemas, com o passar dos anos, o CEBRI não conseguiu atingir plenamente os objetivos inicialmente traçados, embora promova palestras, encontros e realize importantes seminários. Ao mesmo tempo, produz documentos como o recente Relatório sobre os Estados Unidos da América, em agosto de 2002, que teve a colaboração de diversos membros da comunidade acadêmica, jornalística e empresarial (CEBRI, 2002-2003).

Além dessa instituição, não podemos esquecer os departamentos criados para tratar de assuntos internacionais nas inúmeras federações e confederações de comércio e indústria, nas secretarias municipais e estaduais, nas empresas estatais e nos demais órgãos da administração federal direta e indireta, nas universidades, nos sindicatos e nas associações de classes, nos partidos políticos e em outras organizações não-governamentais.

No plano federal vale lembrar a Assessoria de Relações Federativas (ARF) instituída em 09 de junho de 1997 pelo Decreto n. 2 246/97 (BRASIL, 2003). O principal objetivo da ARF, subordinada diretamente ao Gabinete do Ministro das Relações Exteriores, é o de intermediar as relações entre o Itamaraty e os governos de estados e municípios brasileiros, bem como as Assembléias estaduais e municipais, assessorando-os em suas iniciativas externas, tratativas com governos estrangeiros, organismos internacionais e organizações nãogovernamentais. O próprio município de São Paulo criou na atual administração a Secretaria Municipal de Relações Internacionais, enquanto no Rio Grande do Sul, nos anos 1980, uma Secretaria Especial de Relações Internacionais fazia já parte da estrutura administrativa em âmbito estadual no governo de Pedro Simon.

Apenas para complementar, poderíamos mencionar, ainda, a realização de eventos vários, tratando desses temas, como o recente seminário promovido pela PUC paulista e pelo Centro de Estudos e de Cultura Contemporânea (CEDEC), em 09 de dezembro de 2002, versando sobre integração e governos sub-nacionais, quando se discutiu a experiência das cidades latinoamericanas no contexto regional.

O surgimento dos cursos de Relações Internacionais, portanto, insere-se nesse quadro em que o comércio internacional, os intercâmbios políticos, culturais e sociais, a entrada de grandes conglomerados estrangeiros, em praticamente todos os setores - seja adquirindo empresas nacionais, seja associando-se às mesmas -, passaram a assumir importância crescente, causando impacto tanto junto à sociedade quanto no Estado brasileiro. Esse fato (novos cursos e interesse pelas RI) está, destarte, diretamente relacionado ao papel que o país desempenha ou exercitará com maior ou menor intensidade nos próximos anos; à sua inserção em termos regionais ou mais amplos, e à própria percepção que as pessoas passaram a ter do mundo, influenciadas principalmente pelos meios de comunicação de massa que invadiram as casas de todos sem pedir licença.

\section{OS CURSOS DE RIE O PADRÃO DE QUALI- DADE}

Se, de um lado, o cenário parece promissor para o bacharel em Relações Internacionais nesse novo quadro, em que o mercado precisará de profissionais com uma ampla gama de conhecimentos, por outro lado, o surto muito rápido de cursos também tem levantado alguns problemas.

Esses obstáculos estão ligados, fundamentalmente, ao fato de os cursos de RI serem ainda pouco conhecidos no país. Como se sabe, a primeira graduação específica sobre o assunto surgiu em 1974 na Universidade de Brasília, locus privilegiado, e com apenas 20 alunos ingressantes, tendo com o tempo aumentado para 40. Com vestibulares semestrais no período diurno, esses jovens profissionais, na condição de pioneiros, 
rapidamente se inseriram no mercado de trabalho, apresentando uma série de vantagens frente aos demais que agora começam a se formar.

Em primeiro lugar, puderam usufruir da proximidade das várias instâncias governamentais, tendo facilidades para o acesso a informações, contatos e, como resultado, a possibilidade de estágios e empregos na própria cidade, sobretudo em órgãos da administração federal. Em segundo lugar, contaram com a sorte de ter um corpo docente altamente qualificado em Ciência Política e Relações Internacionais - acadêmicos e profissionais provenientes do meio diplomático e outras esferas federais ancoradas em Brasília -, tanto no Departamento de Ciência Política e Relações Internacionais (transformado no Instituto de Ciência Política e Relações Internacionais em 1994, criando-se dois departamentos distintos a partir de então), quanto nos Departamentos de História, Direito e de Economia, ao contrário dos cursos que estão agora sendo criados. Em função disso, puderam ter uma sólida formação. Em terceiro lugar, as turmas de formandos sempre foram pequenas numericamente, ao contrário dos cursos atuais que oferecem pelo menos 50 vagas em cada período. Foram, portanto, privilegiados, e absorvidos sem maiores problemas pelo mercado de trabalho.

Com o passar do tempo, o acervo bibliográfico conseguido pela Universidade de Brasília também tornou-se expressivo, possivelmente o mais completo existente no país na área. Ademais, devese levar na devida conta a existência do próprio Ministério das Relações Exteriores, que acabou favorecendo $o$ acesso a dados principalmente sobre política externa brasileira. Por último, mas não menos significativo, foi o surgimento, na UnB, dez anos depois - em 1984 -, do mestrado específico em Relações Internacionais, primazia que hoje divide com o igualmente bastante solicitado programa de pós-graduação (mestrado) oferecido pelo Instituto de Relações Internacionais da Pontifícia Universidade Católica do Rio de Janeiro (IRI-PUC-Rio) e o mais recente da Universidade Federal do Rio Grande do Sul (UFRGS). A instituição carioca também conta com uma publicação de grande importância para os estudiosos de RI, intitulada Contexto Internacional, uma das principais do país, ao lado de Política Externa, do Núcleo de Pesquisa em Relações Internacionais (NUPRI) da Universidade de São Paulo, e da
Revista Brasileira de Política Internacional e Cena Internacional ${ }^{4}$, ambas da Universidade de Brasília.

Os cursos recentes, por sua vez, têm sido criados e funcionam com algumas deficiências que precisam ser rapidamente solucionadas, sob o risco de comprometer a sua qualidade, prejudicando, portanto, os próprios alunos que ingressam nessas instituições de ensino superior (IES).

Pela Portaria n. 641, de 13 de maio de 1997, da SESu, estabeleceram-se os critérios para a autorização de novos cursos em Relações Internacionais, em faculdades integradas, faculdades isoladas, institutos superiores ou escolas superiores em funcionamento.

De acordo com esta Portaria, as IES interessadas em criar graduação em Relações Internacionais devem preencher padrões mínimos de qualidade, que se podem, resumidamente, arrolar nos seguintes itens (BRASIL, s/d):

1. exigência de coordenador com formação específica na área de Relações Internacionais. Critério idêntico aplica-se ao corpo docente. Tais requisitos levam em consideração a conveniência de se pensar as Relações Internacionais como área distinta de estudo. Conquanto seja um curso que propicie uma formação multidisciplinar, composto por matérias como Economia, Direito, História e Política, isso não deve ser entendido como um mero ajuntamento, ou como uma simples "colcha de retalhos". A obrigatoriedade de especialistas em Relações Internacionais para ministrar as disciplinas que constituem o núcleo do curso tem sua razão de ser: apenas profissionais com sólida formação na área, melhor do que ninguém, podem atender as reais necessidades e demandas do curso. Se o corpo docente dos cursos de Relações Internacionais fosse composto tão-somente por professores de outras áreas, o mesmo critério poderia ser aplicado às demais graduações. Assim, na Portaria n. 641, levanta-se a seguinte questão: seria possível imaginar um curso de Economia cujo corpo docente contasse apenas ou majoritariamente com advogados, sociólogos e historiadores? Critérios semelhantes devem, portanto, ser utilizados para as RI;

\footnotetext{
4 A revista Cena Internacional é eletrônica e pode ser encontrada no seguinte endereço: http://www.relnet.com.br.
} 
2. no que diz respeito à qualificação docente, ela é considerada um requisito básico, condição, aliás, que qualquer curso que tenha entre seus objetivos oferecer um ensino de boa qualidade deveria seguir. Em termos satisfatórios, entendese que um corpo docente precisa apresentar em seu quadro pelo menos $1 / 3$ de professores com a titulação de doutor. Os demais devem possuir os títulos de mestre ou de especialistas. Recomendase que professores sem titulação formal não excedam a 1/3 do total. Entre esses, profissionais que atuam na área, e que têm reconhecida competência, podendo ser incorporados ao quadro docente, desde que em número limitado. $\mathrm{Na}$ aferição da qualidade do corpo docente ponderamse, também, outras atividades, como a produção acadêmica, a participação em pesquisa com apoio institucional e cargos e funções de administração acadêmica;

3. no projeto acadêmico-pedagógico, a estrutura do curso deve apresentar uma grade curricular satisfatória, contemplando disciplinas específicas de Relações Internacionais, disciplinas auxiliares e correlatas, além de outras optativas. As disciplinas específicas visam a preencher as necessidades consideradas mínimas, desde uma disciplina introdutória em RI, aquelas voltadas para o ensino das diversas correntes teóricas, outras de história e análise da política externa brasileira, de história das relações internacionais, além de disciplinas que focalizem sua análise nas instituições políticas e econômicas internacionais. Este primeiro conjunto deve comportar pelo menos 8 disciplinas, com carga de trabalho individual em torno de 60 horas. Num segundo bloco, disciplinas de apoio e diretamente relacionadas às RI devem, obrigatoriamente, incluir matérias introdutórias de Ciência Política, Economia, Direito e Sociologia (ou Filosofia), Teoria Política Moderna e Contemporânea, Metodologia aplicada à Ciência Política e Relações Internacionais, além de Estatística e Métodos Quantitativos, Relações Econômicas Internacionais, Economia Brasileira e Direito Internacional. Esse grupo deve conter em torno de 20 disciplinas com cerca de 60 horas cada. Finalmente, em um terceiro conjunto, cadeiras optativas que atendam as necessidades das próprias instituições, em torno de três disciplinas com carga horária individual aproximada de 60 horas. A inclusão de monografia de fim de curso também é recomendada, nos mesmos moldes de outras graduações;
4. quanto às instalações e recursos de infraestrutura, considera-se item imprescindível a existência de uma biblioteca bem aparelhada que inclua as obras básicas para o bom andamento do curso, suprindo convenientemente as disciplinas com livros e periódicos nacionais e estrangeiros. Devese acrescentar, ainda, a necessidade de acesso à rede mundial de computadores, possibilitando tanto ao corpo discente quanto aos professores obter informações de fontes múltiplas, documentos e materiais de pesquisa, favorecendo o contato com instituições e pesquisadores de outras localidades, do país e do exterior.

Obviamente que a Portaria n. 641, ao estabelecer tais padrões de qualidade, procurou preservar a área de Relações Internacionais, considerando que a mesma apresenta um perfil definido que deve ser acatado pelas instituições interessadas no seu ensino, apesar de não termos formalmente as diretrizes curriculares estabelecidas pelo Ministério da Educação. Isso - a definição das diretrizes curriculares - contribuiria não apenas para solidificar esse campo de atividade, como fundamentalmente para fixar com precisão maior o que se deve entender pelo curso e pelo ensino das Relações Internacionais, diferenciando-o de maneira inequívoca de outros como Comércio Exterior ou Gestão de Negócios Internacionais.

Contudo, o que se observa nos pareceres favoráveis até agora emitidos para a implantação dos cursos em todo o país - anteriormente pela SESu e agora pelo INEP (Instituto Nacional de Estudos e Pesquisas Educacionais) -, é que nem todos têm preenchido de maneira adequada e simultaneamente os requisitos tidos como imprescindíveis pela Portaria n. 641, sobre os critérios de qualidade. Pelos mesmos critérios que definem a capacidade que qualquer instituição tem de melhorar o curso posteriormente - pelo incentivo à contratação $\mathrm{e}$ reforço à titulação do corpo docente, investimentos na biblioteca, melhoria da infra-estrutura etc. - basicamente nos quatro primeiros anos após à sua abertura, e quando for solicitado o seu reconhecimento, que deve ocorrer até o término da primeira turma. Além disso, os quatro itens têm tido pesos diferenciados. No relatório final, computados todos os pontos e por meio de sua ponderação, a instituição solicitante pode ter uma avaliação positiva. Nesse caso a Comissão de Especialistas em Relações Internacionais da SESu - que verifica in loco todas as condições, - 
recomenda sua aprovação, fixando número de vagas, turmas, turnos de funcionamento, conceituando o curso em uma gradação que compreende os níveis A, B e C. Por sua vez, a instituição que tiver uma média ponderada abaixo da exigida é contemplada, obviamente, com a classificação $\mathrm{D}$, tendo suas aspirações bloqueadas pelo menos naquela oportunidade, havendo, portanto, que reformular sua proposta, ou então simplesmente desistir. Ou utilizar, de acordo com o Artigo $3^{\circ}$ da Portaria n. 2 297, de 8 de novembro de 1999, no prazo de cinco dias úteis a partir da entrega do relatório, o expediente de solicitar à SESu a "revisão da avaliação em razão de erro material ou impropriedades no procedimento de verificação" (BRASIL, 1999).

Com a entrada em vigor dos recentes Manuais de avaliação de cursos, elaborados em 2002, que contaram com a colaboração de especialistas de cada área, reunidos em comissões específicas, sob a coordenação do INEP, alguns dos itens anteriores foram repensados e desdobrados em vários tópicos novos. Não só isso, mas uniformizaram-se também os critérios para avaliação de todos os cursos e instituições do país - ressalvando-se obviamente as particularidades de cada carreira -, fazendo-se o mesmo para os próprios avaliadores, que passaram por intenso treinamento ministrado pelo Ministério da Educação. No caso das Relações Internacionais, até agora dez professores de diversas instituições de ensino superior do país fizeram sua capacitação em Brasília nos dias 27 e 28 de agosto de 2002. Para o curso de Relações Internacionais alguns indicadores foram considerados de especial importância ${ }^{5}$. Entre esses, a adequação dos docentes com formação específica nas disciplinas que ministram, a titulação dos professores, o regime de trabalho - priorizando-se a dedicação em tempo integral -, a existência de uma boa biblioteca e instalações satisfatórias.

Pelo fato de os manuais serem ainda recentes, algumas controvérsias têm sido suscitadas, como pode ser visto, por exemplo, no texto de Carlos Costa que elenca não só elogios, mas principalmente críticas de representantes de diversas facul-

\footnotetext{
5 O manual relativo ao curso de Relações Internacionais está disponível, desde o dia 09 de agosto de 2002, no seguinte endereço eletrônico: http://www.inep.gov.br/download/ superior/2002/condicoes_ensino/ACE-REL_INTERNACIONAIS.pdf.
}

dades. Esses contestam muitos dos critérios utilizados pelo INEP para aferir a qualidade dos cursos, pois, segundo eles, agora as instituições particulares foram equiparadas às públicas, apenando-as, portanto, sem levar em conta as especificidades de cada uma delas (COSTA, 2002).

\section{AS DIFICULDADES ENCONTRADAS}

Na maioria das instituições, as deficiências mais agudas dizem respeito ao material bibliográfico e ao corpo docente. Até mesmo universidades conhecidas têm acervo limitado na área específica de RI, com livros e periódicos aquém do necessário inclusive para implementar os primeiros anos do curso. Quando se trata de faculdades isoladas, a situação é ainda mais sofrível, visto que grande parte delas não apresenta sequer bibliografia adequada, referente às disciplinas conexas. Das avaliações dos especialistas que visitam as instituições naturalmente constam essas ressalvas, chamando-se atenção para a necessidade de se implementarem medidas urgentes visando à aquisição de livros e periódicos considerados básicos, bem como a formulação de uma política de atualização permanente do acervo. Como se pode daí depreender, o não preenchimento deste requisito implica a queda de qualidade dos cursos, impossibilitando que os alunos tenham acesso a obras fundamentais das Relações Internacionais, muitas delas fáceis de obter. Várias dessas obras foram inclusive traduzidas pela Editora da Universidade de Brasília nos anos 1980, sendo que, desde o começo de 2002, dispõe-se uma coleção básica de 20 textos para o público pela mesma editora, em conjunto com o Instituto de Pesquisa em Relações Internacionais do Ministério das Relações Exteriores, e com a Imprensa Oficial do Estado de São Paulo. O não cumprimento deste tópico significa, ainda, que as faculdades, ao aproximarse a formatura das primeiras turmas de alunos, poderão ter problemas quando solicitarem o reconhecimento do curso, feito pelos avaliadores do INEP, se além desse quesito outros não tiverem sido preenchidos satisfatoriamente durante o decorrer dos primeiros anos.

Na realidade, a questão do acervo é um dos indicadores complicados para a aferição feita pelos especialistas de praticamente todas as áreas que assessoram o Ministério da Educação, tanto para efeito de autorização de funcionamento do curso quanto para seu posterior reconhecimento.

Sabendo que muitas instituições de ensino 
superior apresentam dificuldades para atender todos os requisitos exigidos, os próprios membros do Conselho Nacional de Educação procuraram estabelecer critérios menos rigorosos para a abertura e funcionamento de novos cursos, afrouxando, por exemplo, as exigências no que se refere à aquisição de material bibliográfico, ou mesmo da estrutura curricular de alguns bacharelados.

Pelo Parecer n. 146, de maio de 2002, o Conselho Nacional de Educação flexibilizava os currículos de diversos cursos, como os de Direito, Administração, Ciências Contábeis, Música, Teatro e Economia. Por meio de liminar da Ordem dos Advogados do Brasil, contudo, o Superior Tribunal de Justiça suspendeu, no dia 10 de setembro do mesmo ano, o parecer do Ministério da Educação. Manteve-se, assim, pelo menos temporariamente, a premissa de que o bacharelado em Direito deve ter um currículo mínimo para formação de seus profissionais, ao contrário do que defendia o Ministério da Educação (CONSELHO NACIONAL DE EDUCAÇÃO, 2002; cf. também SOUZA, 2002, p. A-13).

Já segundo o Parecer CES n. 1 070/99, aprovado em 23 de novembro de 1999, cujo assunto eram os critérios adotados para autorização e reconhecimento de cursos de Instituições de Ensino Superior, a Câmara de Ensino Superior do Conselho Nacional de Educação manifestava preocupação junto à SESu quanto às abordagens diferentes utilizadas pelas diversas Comissões de Especialistas e de Verificação, consideradas extremamente heterogêneas (CONSELHO NACIONAL DE EDUCAÇÃ O, 1999).

De acordo com os conselheiros, era "preciso maior comedimento na exigência de múltiplos exemplares dos livros indicados na bibliografia". Continuando, o relatório mencionava, ainda, que "a bibliografia básica dos cursos é freqüentemente alterada porque deve ser atualizada constantemente e a multiplicação de textos desatualizados no acervo constitui um investimento pouco produtivo. Além do mais é preciso que a atualização e a relevância das obras do acervo recebam consideração maior que o número de livros existentes". Assim, "tanto no caso das bibliotecas como na infra-estrutura de informática o melhor é exigir a previsão de recursos permanentes para melhoria, atualização e ampliação do acervo e dos equipamentos" (ibidem).

Ainda que os relatores conselheiros pudessem ter razão quanto à exigência de acervo numeroso - com muitos exemplares de mesma obra -, nada justifica que grande parte das instituições faça seus pedidos de autorização para funcionamento de cursos, ou de seu reconhecimento, sem contar com um mínimo de livros considerados chaves. Sem isso, obviamente, a qualidade do curso fica seriamente comprometida, prejudicando o maior interessado na obtenção de informações e conhecimentos, ou seja, o aluno.

De acordo com o novo Manual de avaliação do curso de Relações Internacionais (INEP, 2002), para que o item "biblioteca" seja considerado "muito bom", a mesma deverá funcionar pelo menos 14 horas diárias, permanecer aberta aos sábados, apresentar possibilidade de reservas de livros pela internet, acesso a base de dados, ter em seu acervo quantidade de livros que atendam aos programas das disciplinas, que haja quantidade suficiente (na proporção de um exemplar por até dez alunos matriculados no curso para qualquer dos títulos selecionados pelo docente da disciplina) e que estejam atualizados, além de manter assinaturas de pelo menos 5 jornais e 5 revistas adequados à proposta pedagógica do curso.

Se as bibliotecas têm se constituído em um dos elementos altamente negativos de diversas instituições que oferecem os cursos de Relações Internacionais, a deficiência do corpo docente também tem sido uma constante. Esse ponto fraco, contudo, pode ser um pouco amenizado, justificado pela relativa carência ainda de professores e especialistas em todo o país que possa atender a demanda tão repentina. Pelo fato de os cursos, bem como a própria área de Relações Internacionais no país, serem recentes, o número de programas com capacidade de formar mestres e doutores é ainda reduzido.

Excluindo-se os mestrados encontrados na Universidade de Brasília, no Instituto de Relações Internacionais da PUC do Rio de Janeiro, e na Universidade Federal do Rio Grande do Sul, as demais instituições oferecem poucas opções, além daquelas relacionadas à integração regional, não apresentando áreas de concentração mais solidificadas em Relações Internacionais em seus currículos.

No programa mais antigo - o da Universidade de Brasília, funcionando desde 1984 -, os profissionais egressos da pós-graduação na sua maioria já encontram trabalho, por exemplo na própria 
Capital Federal. Com os do Rio de Janeiro acontece o mesmo, sendo que muitos alunos que aí completaram seus mestrados igualmente fizeram ou estão realizando seus doutorados em RI ou em Ciência Política, tanto no país quanto no exterior, terminando por ser absorvidos pela própria universidade ou por alguma outra dos grandes centros, como São Paulo ou Belo Horizonte.

As demais instituições que estão oferecendo a graduação em RI, portanto, ao constituírem seu corpo docente têm tido dificuldades em arregimentar recursos humanos suficientes - embora existam alguns aqui, outros acolá, e em número mais limitado do que as outras áreas mais tradicionais - para ministrar inclusive as disciplinas básicas como Teorias das Relações Internacionais, Introdução às Relações Internacionais ou Organizações Internacionais e Política Externa Brasileira.

Um elemento que se pode considerar agravante, na busca de docentes qualificados em RI, é que esses profissionais, além de pouco numerosos, relutam em locomover-se para lugares mais distantes dos grandes centros urbanos, pelo menos por dois motivos. Um deles é o receio de não encontrarem ambiente considerado satisfatório para o pleno exercício de suas atividades, correndo o risco de rapidamente ficarem desatualizados, em virtude da dificuldade de participarem com a freqüência desejada de eventos relacionados à sua área, perdendo os contatos já estabelecidos. $\mathrm{O}$ outro motivo é de ordem pecuniária, por não perceberem vantagens suficientes que consideram importantes como contrapartida, para deixar os locais onde se encontram baseados, já que os salários oferecidos não são considerados atraentes, preferindo manter-se no local de origem.

Assim, durante algum tempo, os cursos sofrerão prejuízos, com poucas possibilidades de contar em seus quadros, a curto prazo, com profissionais titulados tanto em Relações Internacionais quanto oriundos da Ciência Política, Sociologia ou áreas conexas, com domínio de conhecimentos mais rigorosos sobre assuntos internacionais, que possam dar conta das disciplinas específicas.

Há necessidade, entretanto, de as IES esforçarem-se mais e investir na contratação de professores que estão disponíveis, oferecendo política salarial satisfatória, incentivando-os a fazer parte de seus quadros, sem os quais jamais haverá melhoria de qualidade, uma vez que o corpo do- cente é a espinha dorsal do curso.

A própria Universidade de Brasília, em seus inícios, igualmente enfrentou problemas do gênero. Ao contrário, porém, das demais instituições de ensino, sua localização estratégica junto às instâncias de poder facilitou a incorporação em seu corpo docente de pessoal altamente qualificado na área de Relações Internacionais, vindo sobretudo do Instituto Rio Branco e dos demais departamentos do Ministério das Relações Exteriores, ou de outras instâncias ligadas ao Direito Internacional e à História.

Há, contudo, algumas notícias alentadoras. Uma delas é a criação recente dos Doutorados em Relações Internacionais no IRI-PUC-Rio, funcionando desde agosto de 2001, com um sólido corpo docente constituído por dez professores; e o da Universidade de Brasília, desde março de 2002, cujo programa foi criado com professores não só do Departamento de Relações Internacionais mas também do de História. Destarte, essas duas instituições situam-se na vanguarda da área de Relações Internacionais no país, uma vez que a UnB tem os três níveis (graduação, mestrado e doutorado), o mesmo acontecendo em breve com a Pontifícia Universidade Católica do Rio de Janeiro, já que a graduação em RI também começará a ser oferecida a partir de março de 2003.

A outra novidade é que a Coordenação de Aperfeiçoamento de Pessoal de Ensino Superior (CAPES) concedeu recursos, em 2001, para um programa de incentivo à formação de recursos humanos em Relações Internacionais, denominado Programa San Thiago Dantas, tendo financiado quatro propostas para criação e/ou reforço de pósgraduações. Duas delas já foram citadas neste texto. A primeira foi o doutorado em RI da UnB; a segunda foi o mestrado da UFRS; a terceira é uma experiência inédita, ou seja, um programa interinstitucional de pós-graduação em Relações Internacionais envolvendo três grandes universidades paulistas simultaneamente: a UNESP, a PUC-SP e a Universidade Estadual de Campinas (UNICAMP). Nesse modelo o programa será ministrado em nível de mestrado num primeiro momento (com previsão de início para março de 2003, na cidade de São Paulo), seguindo-se depois o de doutorado (provavelmente a partir de 2006); a última proposta que obteve recursos foi a da Universidade Federal Fluminense que também deverá ter as Relações Internacionais como campo importante de investi- 
gação e docência, com o mestrado sendo oferecido a partir de 2003, ampliando sua atuação, um pouco tímida até agora.

\section{PERSPECTIVAS DO MERCADO DE TRABA- LHO}

Apesar de a estrutura dos cursos apresentarse como uma das questões que mais apreensão tem causado tanto aos alunos quanto aos especialistas no ensino em Relações Internacionais, outros assuntos têm, igualmente, merecido atenção, fundamentalmente por parte dos estudantes: os temas da profissionalização e do mercado de trabalho. As dúvidas levantadas abarcam desde a própria designação do egresso do curso - sem denominação como os profissionais de outras áreas, apenas identificado como "internacionalista", suscitando algumas discordâncias - até propostas de criação de uma reserva de mercado (ALMEIDA, 1999a, p. 13).

Esta última idéia, todavia, não tem recebido boa receptividade dos profissionais mais antigos que operam na área, até porque é complicado definir com rigor qual o campo de atuação que poderia ficar apenas aos cuidados do especialista em relações internacionais, procedente desses cursos. Há alguns anos um deputado catarinense apresentou à Câmara dos Deputados projeto de lei visando à regulamentação da profissão de bacharel em Relações Internacionais, estabelecendo suas áreas de competência. Após muitas discussões feitas pelos diversos cursos de RI, os estudantes decidiram na VII Reunião do Conselho Nacional de Estudantes de Relações Internacionais (CONERI), realizada em Belo Horizonte, entre os dias 7 e 9 de setembro de 2000, com a participação de 12 faculdades filiadas à Federação Nacional dos Estudantes de Relações Internacionais (FENERI), manifestar postura contrária à regulamentação da carreira, tendo sido solicitado ao Deputado Antônio Carlos Konder Reis, autor do projeto, sua retirada da pauta da Câmara dos Deputados. O projeto de lei, de 1999, dispunha sobre o exercício da profissão de bacharel em Relações Internacionais e autorizaria a criação dos respectivos Conselho Federal e Conselhos Regionais dos profissionais de RI.

É claro que as preocupações com o mercado de trabalho justificam-se quando um aluno termina sua graduação, e que atinge praticamente de maneira igual a todos os formandos. Trata-se, inquestionavelmente, de uma apreensão mais do que legítima. Porém, ao invés de simplesmente enveredar por discursos dessa natureza, ou ficar infinitamente fincando pé nessas discussões, quiçá fosse mais produtivo trilhar por outros caminhos: que os responsáveis pelos cursos, coordenadores ou diretores, trabalhassem junto às suas comunidades e empresas, procurando explicar adequadamente o que é um profissional de Relações Internacionais, o que o mesmo pode fazer, quais suas habilidades, suas ferramentas de trabalho e sua utilidade no mundo atual, em que as mudanças processam-se com rapidez cada vez maior (SATO, 1999). Isso poderia ser feito, por exemplo, obtendo-se uma listagem de empresas médias e grandes de suas regiões e encaminhando-lhes folhetos, material explicativo etc.

Nessa direção, o Estatuto do Centro Acadêmico do Curso de Relações Internacionais (CARINTER) da Universidade do Vale do Itajaí (UNIVALI), é esclarecedor, já que explicita em seu Artigo $4^{\circ}$, inciso VIII, como um dos seus princípios norteadores, "promover e divulgar o Curso de Relações Internacionais junto à sociedade" (CARINTER, s/d, p. 1).

Talvez seja esse um dos caminhos. Ao invés de tão-somente esperar pela ação dos responsáveis pelos cursos, os próprios alunos, como interessados maiores, poderiam agir no sentido de divulgar cada vez mais o que é e o que faz o profissional de Relações Internacionais. Como se sabe, há bastante tempo os alunos têm mostrado ótima capacidade organizacional e se reunido em foros diversos, seja nos Encontros Nacionais dos Estudantes de Relações Internacionais (ENERI), seja nos Encontros de Estudantes e Graduados em Relações Internacionais do Cone Sul, encontrando-se reunidos por meio da FENERI e do CONERI. Os eventos promovidos desde 1996 em Brasília, Belo Horizonte, São Paulo, Florianópolis, Salvador, Curitiba, ou Rio de Janeiro são claros exemplos de que os estudantes têm forjado, por conta e risco próprios, boas condições para promover e tornar cada vez mais conhecido o ensino das Relações Internacionais no país. Claro que a atuação conjunta com as direções dos cursos favorecerá ainda mais esse tipo de trabalho.

Atividades paralelas às salas de aulas, como laboratórios, jornais e empresas júnior podem, certamente, dar contribuição significativa, ajudando a impulsionar ainda mais o desenvolvimento da área de Relações Internacionais. Na Universidade 
de Brasília, por exemplo, existia uma empresa júnior denominada "Rel Júnior - Consultoria Internacional" e que foi inclusive uma das organizadoras do I Congresso Brasileiro de Relações Internacionais realizado na capital federal em março de 1998. Iniciativas semelhantes existem em diversas faculdades de RI do país. Na PUC de São Paulo foi criado, também em 1999, o Observatório de Relações Internacionais, responsável pela publicação do boletim Observatório Internacional, de periodicidade trimestral e elaborado pelos integrantes do Projeto de Integração Graduação-PósGraduação em Relações Internacionais (PROIN).

Esse tipo de atuação, além de interessante, torna-se necessário porque atinge uma população externa mais ampla, até agora pouco voltada ou informada sobre o curso ou seus problemas, tanto da grade curricular quanto de conteúdo. Em outra esfera, o papel desempenhado pelo RelNet (Sítio brasileiro de referência em Relações Internacionais) dispondo dados os mais variados possíveis, sob a chancela do Departamento de Relações Internacionais da Universidade de Brasília, em colaboração com a Fundação Alexandre de Gusmão (FUNAG), pelo Mercobol da PUC-MG e pela FENERI ${ }^{6}$, entre outros, tem sido de suma importância. Nesses sítios pode-se obter não só informações sobre seminários, cursos de extensão, de pós-graduação no país e no exterior, pesquisas realizadas e em andamento, teses etc., mas participar também de foros de debates com diversos professores, e ler publicações tanto do Ministério das Relações Exteriores quanto da própria UnB.

\section{OBSERVAÇÕES FINAIS}

O campo de trabalho para os "internacionalistas" - à falta de uma designação melhor nos próximos anos deverá ser promissor, já que a falta de pessoas com formação sólida na área é patente, e o momento pelo qual passamos exige crescentemente profissionais com perfil mais amplo. Tudo parece favorecer a participação cada vez maior, em todos os níveis, dos egressos dos bacharelados de RI.

Como qualquer área que procura firmar-se, as RI enfrentarão, também, durante certo tempo, alguns problemas, mencionados anteriormente,

\footnotetext{
6 Seus endereços eletrônicos são: RelNet: http:// www.relnet.com.br; Mercobol: http://www.pucminas.br/ Mercosul, e FENERI: http://www.feneri.com.br.
}

que, espera-se, não demorarão a ser solucionados, como a deficiência do corpo docente e de acervo bibliográfico que algumas instituições têm apresentado.

Por outro lado, deve-se ponderar, realisticamente falando, que muitas das atuais instituições que não conseguirem suprir essas deficiências de maneira adequada e persistirem fornecendo cursos com qualidade abaixo daquela que poderia ser considerada razoável, correrão o risco de não terem, depois de alguns anos, alunos suficientes para assegurar sua continuidade.

A abertura de muitos cursos em uma única cidade também deverá acarretar o mesmo problema, já que poderá ocorrer a insuficiência de demanda para preencher todas as vagas existentes, o que nos anos vindouros comprometerá o planejamento orçamentário da instituição, obrigandoa a tomar medidas mais drásticas.

Mesmo em cidades médias onde existam um ou dois cursos de RI, as instituições poderão encontrar dificuldades para mantê-los em funcionamento após algum tempo - isso já está ocorrendo - caso os egressos não consigam ser contratados em período razoável na própria cidade ou região, em um raio não muito distante. Neste último caso, se for pensado o deslocamento do profissional formado em cidades médias para centros urbanos maiores, como as capitais dos estados, sua formação deverá ser muito boa para compensar possíveis desvantagens, porque terá que competir com colegas de tradicionais universidades. Estas, como se sabe, por uma série de fatores, têm demonstrado possibilidade de oferecer, comparativamente, cursos bastante sólidos, além dos contatos que só grandes centros propiciam. Os próximos cinco anos serão decisivos para termos um quadro mais definido e sabermos com maior precisão quais cursos sobreviverão frente a essas adversidades.

O quadro existente antes de 1995 e o posterior são bastante diferentes. Os cursos existentes até meados dos anos 1990, como o da UnB e da Universidade Estácio de Sá (UNESA), apesar de já serem conhecidos, eram contudo identificados, pela maior parte da população, como tendo objetivos mais específicos: a primeira voltada para fornecer futuros quadros para o Ministério das Relações Exteriores, e a segunda mais preocupada com as técnicas e negociação de comércio exterior. 
A explosão dos cursos de RI a partir de 1995 , primeiramente com a PUC paulista e no ano seguinte com a abertura do curso da PUC mineira, serviu para derrubar algumas informações equivocadas, mostrando, em primeiro lugar, que a finalidade dos cursos, tanto da UnB quanto da UNESA, não tinham atuações tão restritas, como as que muitos pensavam, "formando" apenas futuros diplomatas ou técnicos em comércio exterior. Em segundo lugar, demonstrando que o campo de atuação desses profissionais é extremamente aberto, sendo que os egressos de RI são detentores de um conjunto de informações que nenhuma outra modalidade de bacharelado oferece, o que os torna altamente competitivos no mercado de trabalho.

Certamente que apenas o acúmulo de informações no plano estritamente teórico, a longo prazo, ou mesmo a médio e curto prazos, demonstrar-se-á insuficiente para que o formando do curso de RI dispute postos nos mais diferentes setores, com chances de sucesso, a não ser que se dedique a atividades acadêmicas ou de pesquisas, fundamentalmente em instituições universitárias ou em órgãos governamentais como o Congresso Nacional.

Como bem chama atenção o diplomata Paulo Roberto de Almeida, que alia a prática da negociação como funcionário do Itamaraty à atividade desenvolvida em várias instituições de ensino superior, "uma trading por exemplo, ou seja, uma empresa de comércio exterior não se dispõe a contratar um profissional apenas em virtude de um brilhante currículo acadêmico, mesmo se ele for egresso de uma conceituada faculdade pública. Ela é bem mais propensa a valorizar o conhecimento prático da nomenclatura aduaneira, da regulamentação de comércio exterior, das normas técnicas em vigor nos mercados estrangeiros" (ALMEIDA, 1999a, p. 13).

É isso que se espera de um bom profissional das Relações Internacionais, independentemente da opção de trabalho que deseja desenvolver: o domínio da teoria, crucial para entender e interpretar as grandes mudanças que se processam no cenário nacional regional e mundial, e, também, o conhecimento prático que tanto interessam às empresas do setor comercial e industrial, nacionais e estrangeiras, às agências de fomento, às instâncias governamentais e às organizações não-governamentais.

Claro que o domínio de todos esses requisitos é difícil, mesmo moroso, levando algum tempo, principalmente para um recém-formado. Consciente disso, o aluno desde o momento em que ingressa no curso tem que procurar obter o máximo de informações possível, manter-se atualizado, realizar estágios, dedicar parte apreciável de seu tempo às leituras necessárias, participar de eventos e, na medida do possível, estar atento às possibilidades de viagens, tanto no país quanto para o exterior, visando ampliar a cada vez mais seu leque de opções. Mas não é isso que ocorre, também, com grande parte das demais profissões?

Shiguenoli Miyamoto (shiguenoli@globo.com; shigue@unicamp.br) é Professor Livre-Docente/Associado do Departamento de Ciência Política da Universidade Estadual de Campinas (UNICAMP) e membro do Centro de Estudos Internacionais e de Política Contemporânea (CEIPOC-UNICAMP).

\section{REFERÊNCIAS BIBLIOGRÁFICAS}

ALMEIDA, P. R. 1999a. Profissionalização em relações internacionais : uma discussão inicial. Observatório Internacional, São Paulo, n. 1, p. 13, out.-dez.

1999b. O estudo das Relações Internacionais do Brasil. São Paulo : Unimarco.

BRASIL. Ministério das Relações Exteriores. 2003. Assessoria de relações federativas. http:/ /www.mre.gov.br/federativas.htm. Acesso em : 16.fev.2003.
BORGES, J. P. 1999. Diplomacia pública e democracia. Network, Rio de Janeiro, v. 8, n. 4, p. 3, out.-dez.

CARINTER, s/d. Estatuto do Centro Acadêmico de Relações Internacionais da Universidade do Vale do Itajaí. http://pagina.de/carinter. Acesso em : 16.fev.2003.

CEBRI. 2002-2003. Relatório sobre os EUA elaborado por força-tarefa independente, patro- 
cinada pelo Centro Brasileiro de Relações Internacionais (CEBRI). Política Externa, São Paulo, v. II, n. 3, p. 114-135, dez.-fev.

COSTA, C. 2002. Avaliar ou punir. Ensino Superior, São Paulo, ano 5, n. 50, p. 16-19. http:// www.ensinosuperior.com.br/apresenta2.php?pag_id=272\&edicao $=50$. Acesso em : 16.fev.2003.

INEP. 2002. Manual de avaliação do curso de Relações Internacionais. Brasília : Instituto Nacional de Estudos e Pesquisas Educacionais. http://www.inep.gov.br/download/superior/ 2002/condicoes_ensino/ACE-REL_INTERNACIONAIS.pdf. Acesso em : 16.fev.2003.

LAMPRÉIA, L. F. 2000. Cúpula da América do Sul. O Estado de S. Paulo, 31.mar., p. A-2.

MEDEIROS, A. P. C. 1979. Relações Internacionais como disciplina acadêmica : origem, conteúdo, importância e atualidade. Direito e Justiça, Porto Alegre, v. 1, n. 2, p. 44-63, $2^{\circ}$ semestre.

MIYAMOTO, S. 1999. O estudo das Relações Internacionais no Brasil : o estado da arte. Re- vista de Sociologia e Política, Curitiba, n. 12, p. 83-98, jun.

ROSSI, C. 2000. Brasil terá cúpula sul-americana. Folha de S. Paulo, 26.mar., p. 01-05.

SATO, E. 1999. Os desafios para a formação de uma identidade comum no ensino de Relações Internacionais. Texto apresentado no V Encontro de Estudantes e Graduados em Relações Internacionais do CONESUL, realizado em Brasília em 30 de outubro de 1999. Digit.

SOUZA, M. M. 2002. Liminar da OAB tenta assegurar currículo mínimo. $O$ Estado de $S$. Paulo, 18.set., p. A-13.

VASCONCELOS, M. E. 1999. O que vamos ser quando crescer? O Estado de Minas, 22.mar.

VIEIRA, J. R. 1983. O ensino das Relações Internacionais no Brasil. Texto apresentado ao Grupo de Trabalho Relações Internacionais e Política Externa do Brasil no VII Encontro Anual da Associação Nacional de Pesquisa e Pós-graduação em Ciências Sociais, realizado em Águas de São Pedro (SP), de 26 a 28 de outubro de 1983. Mimeo.

\section{OUTRAS FONTES}

\section{CONSELHO NACIONAL DE EDUCAÇÃO.} Câmara de Ensino Superior. 1999. Parecer n. 1 070/99, que trata dos "Critérios para autorização e reconhecimento de cursos de Instituições de Ensino Superior". Relatores : Eunice Ribeiro Durham, Lauro Ribas Zimmer, Arthur Roquete de Macedo e Yugo Okida. Homologado pela Ministra da Educação Interina Maria Helena Guimarães de Castro. Diário Oficial da União, Brasília, 23.nov.

2002. Parecer n. 146 de 03 de abril. Relatores : José Carlos Almeida da Silva e Lauro Ribas Zimmer. Homologado pela Ministra da Educação Interina Maria Helena Guimarães de
Castro. Diário Oficial da União, Brasília, 13.maio, seção 1, p. 21.

BRASIL. Ministério da Educação. Secretaria de Educação Superior. s/d. Padrões de qualidade para os cursos de Relações Internacionais. Brasília : Ministério da Educação. http:// www.mec.gov.br/sesu/ftp/padreli.doc. Acesso em : 16.fev.2003.

1999. Portaria n. 2 297, de 8 de novembro. Dispõe sobre a constituição de comissões e procedimentos de avaliação e verificação de cursos superiores. Brasília : Ministério da Educação. http://www.mec.gov.br/Sesu/credenc.shtm\#legisla. Acesso em : 16.fev.2003. 